\title{
PERANCANGAN SISTEM INFORMASI MANAJEMEN \\ PENERIMAAN MAHASISWA BARU PADA \\ UNIVERSITAS “WR. SUPRATMAN" SURABAYA
}

\author{
Suwito Widodo, Dedy Kunhadi \\ Jurusan Teknik Industri \\ Universitas WR. Supratman Surabaya \\ Email : nur.rafiansyah02@gmail.com
}

\begin{abstract}
ABSTRAK
$\mathrm{P}$ enerimaan mahasiswa baru Universitas WR. Supratman Surabaya masih menggunakan cara manual dan melalui proses yang memakan waktu. Hal ini terkadang masih terdapat kekurangan-kekurangan, seperti sering terjadinya duplikasi data, keterlambatan laporan, dll. Oleh karena itu, perlu Perancangan Sistem Informasi Manajemen penerimaan mahasiswa baru Universitas WR. Supratman Surabaya yang berguna meningkatkan mutu pelayanan dan pengolahan data yang lebih baik serta memiliki keakuratan yang lebih tinggi. Penelitian ini menggambarkan prosedur Sistem Penerimaan Mahasiswa Baru pada Universitas WR. Supratman Surabaya, kemudian menentukan file-file database sampai atribut-atribut yang diperlukan pada sistem tersebut. Kemudian membuat suatu program pengolahan data dengan mempergunakan bahasa Visual Foxpro 6.0 sebagai fasilitas penunjang Sistem Penerimaan Mahasiswa Baru pada Universitas WR. Supratman Surabaya.
\end{abstract}

Kata Kunci : DFD, ERD, Normalisasi, Desain (Input/Output, Kode ), Struktur Program

\section{PENDAHULUAN}

Universitas WR. Supratman Surabaya selalu menekankan kualitas kerja para pegawai, pelayanan terhadap mahasiswa guna meningkatkan kualitas sumber daya manusia, baik para tenaga pendidik maupun para mahasiswanya sendiri. Berkaitan dengan hal itu, berbagai sarana dan prasarana yang terkait didalamnya baik sumber daya maupun perangkat lainnya harus dipersiapkan untuk mendukung tercapainya tujuan itu, khususnya dalam memberikan pelayanan dengan sebaikbaiknya guna memberikan kepuasan kepada semua pihak.

Oleh karena itu sistem pengolahan data harus diperhatikan, karena apabila sistem pengolahan data tidak ditangani dengan serius dan profesional maka besar kemungkinan permasalahanpermasalahan pada pengolahan data akan muncul, yang mungkin akan menyulitkan pihak Universitas WR. Supratman Surabaya sendiri.

Maka dalam usaha memperbaiki pengolahan data tersebut, maka perlu perancangan sistem 100 informasi manajemen penerimaan mahasiswa baru pada Universitas WR. Supratman Surabaya, dengan maksud berusaha untuk membantu dalam memberikan pelayanan dan pengolahan data yang baik berupa sistem komputerisasi yang mudah dimengerti dan diterapkan.

\section{TINJAUAN PUSTAKA}

\section{Sistem Informasi Manajemen}

Sistem Informasi Manajemen (Management Information Sistem atau sering dikenal dengan singkatan SIM) merupakan penerapan sistem informasi didalam organisasi untuk mendukung informasi-informasi yang dibutuhkan oleh semua tingkatan manajemen.

Dalam buku Jogiyanto Hartono (1999), Sistem informasi manajemen digambarkan sebagai struktur pyramid, pada lapisan bawah disebut manajemen tingkat bawah (lower level management), terdiri dari sumber informasi yang mendukung operasi sehari-hari dan pengawas, dapat meliputi mandor dan pengawas. Level berikutnya disebut 
manajemen tingkat menengah (middle level management), terdiri dari sumber sistem informasi untuk membantu perencanaan taktis dan pengambilan keputusan untuk pengawasan manajemen, meliputi manajer-manajer devisi dan manajer cabang. Dan pada level tertinggi disebut manajemen tingkat atas (top level management) terdiri dari sumber informasi untuk mendukung strategi perencanaan dan perumusan kebijaksanaan oleh levellevel manajemen yang lebih tinggi, terdiri dari direktur utama, direktur, dan eksekutif lainnya. Masing-masing level dari pengolahan informasi menyediakan data yang digunakan bagi tingkatan yang lebih rendah; tetapi data baru juga boleh diperkenalkan.

Data merupakan suatu inputan yang nantinya akan diproses melalui suatu model dan seterusnya membentuk suatu siklus dan menurut John Burch dalam buku Jogiyanto Hartono (1999) siklus ini disebut siklus informasi (information cycles). Adapun siklus tersebut dapat dilihat pada gambar 1:

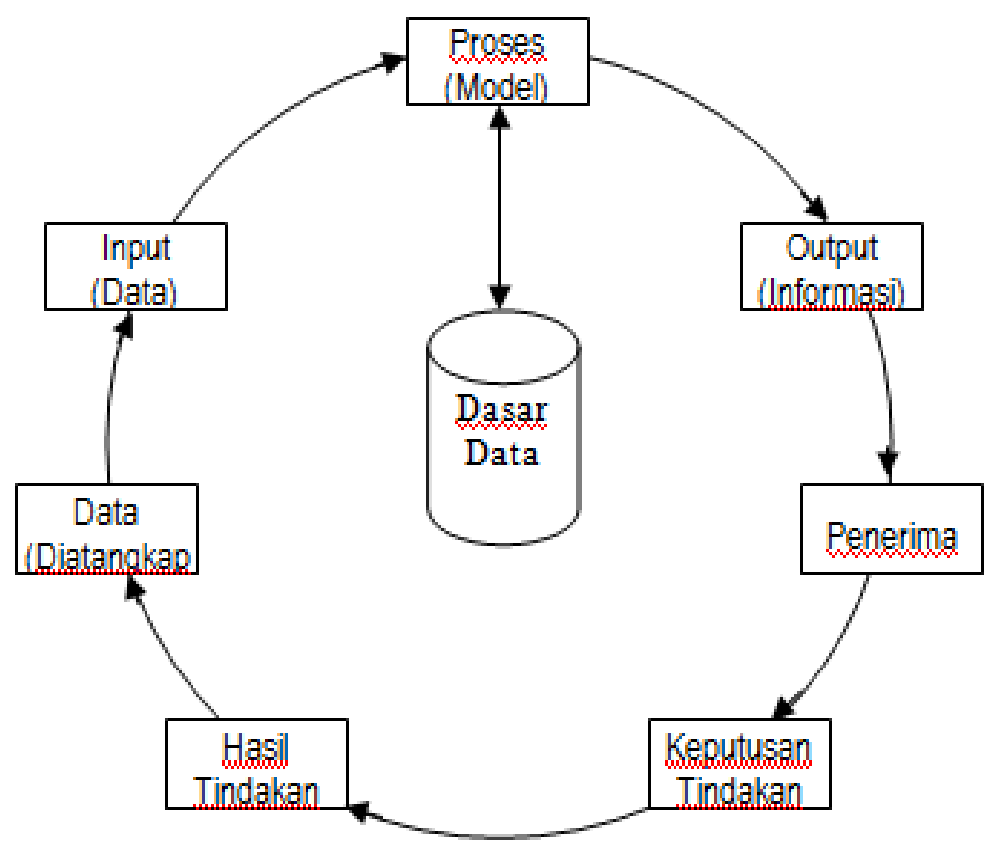

Gambar 1 Siklus Informasi

\section{Data Flow Diagram (DFD)}

Dalam buku HM. Jogiyanto (1993), Data Flow diagram adalah penggambaran suatu prosedur sistem informasi dalam suatu bagan untuk mewakili arus data dengan menggunakan simbol-simbol atau notasi tertentu. Penggunaan notasi dalam diagram arus ini sangat membantu sekali untuk memahami suatu sistem pada semua tingkat kompleksitasnya.

DFD sering digunakan untuk menggambarkan suatu sistem yang telah ada ataupun sistem yang baru akan dikembangkan tanpa mempertimbangkan lingkungan fisik dimana data tersebut itu mengalir.
DFD merupakan alat yang digunakan pada metodelogi pengembangan sistem yang terstruktur (Struktur Analis Design). DFD merupakan alat yang popular, karena dapat menggambarkan arus data didalam sistem dengan terstruktur dan jelas.

\section{Entity Relationship Diagram (ERD)}

Dalam buku Tavri D. Mahyusir (1989), Entity Relationship Diagram (ERD) adalah suatu model jaringan yang menggunakan susunan data yang diwujudkan dalam bentuk diagram. Jadi jelas bahwa ERD berbeda dengan DFD yang merupakan suatu model jaringan fungsi data yang 
menekankan pada struktur-struktur dan hubungan data. ERD juga menguntungkan dalam perancangan suatu sistem, karena ERD memperlihatkan hubungan antara data store pada DFD, karena hanya memusatkan perhatian pada fungsi-fungsi sistem dan bukan pada data yang dibutuhkan.

\section{Normalisasi}

Dalam buku Jogiyanto Hartono (1999), proses normalisasi merupakan proses pengelompokan data elemen tabel-tabel yang menunjukkan entitas dan relasinya, konsep yang ada pada normalisasi :

1. Field atau atribut kunci

- Kunci Calon (Candidate Key), merupakan satu atribut atau satu set atribut yang mengidentifikasi secara unik suatu kejadian spesifik dari entitas.

- Kunci Primer (Primary Key), merupakan satu atribut atau satu set atribut yang tidak hanya mengidentifikasikan secara unik suatu kejadian spesifik, tetapi juga mewakili setiap kejadian dari suatu entitas.

- Kunci Alternatif (Alternate Key), merupakan kunci kandidat yang tidak dipakai sebagai kunci primer, kunci ini digunakan sebagai pengurutan dalam penyusunan laporan.

- Kunci Tamu (Foreign Key), merupakan suatu atribut yang melengkapi suatu hubungan yang menunjuk kepada induknya, Foreign Key ditempatkan pada item "anak" dan sama dengan Primary Key. Hubungan antara item "induk" dengan "anak" adalah hubungan satu ke banyak (one to many relationship).

- Super Key, adalah himpunan dari satu atau lebih entitas yang dapat digunakan untuk mengidentifikasi secara unik sebuah entitas dalam entitas atau entity enterprise.

1. Ketergantungan fungsi diberikan sebuah relasi $\mathrm{R}$, atribut $\mathrm{Y}$ dan $\mathrm{R}$ adalah bergantung fungsi pada atribut dari $\mathrm{R}$ jika hanya setiap nilai $\mathrm{X}$ dalam $\mathrm{R}$ punya hubungan dengan tepat suatu nilai Y dalam R (dalam setiap waktu).

2. Bentuk-bentuk normalisasi

Dalam buku Tata Sutabri (2003); normalisasi dibagi ke dalam beberapa tingkatan-tingkatan, yaitu :

a. Bentuk tidak normal (Unnormalized Form).

Yaitu kumpulan data yang akan direkam, tidak ada keharusan mengikuti format tertentu, dapat saja data tidak lengkap atau terduplikasi. Data dikumpulkan apa adanya sesuai dengan kedatangannya.

b. Bentuk normal ke satu ( $1 \mathrm{NF}$ / First Normal Form).

Yaitu memiliki ciri setiap data dibentuk dalam flat file (file datar/ rata), datadibentuk dalam satu record demi satu record dan nilai dari field-field yang berupa "atomic value". dimana tidak ada file atribut yang berulang atau bernilai ganda (multi value).

c. Bentuk normal kedua ( $2 \mathrm{NF}$ ).

Mempunyai syarat yaitu bentuk data yangtelah memenuhi kriteria bentuk tidak normal kesatu. Atribut bukan kunci haruslah bergantung secara fungsi pada kunci utama (Primary Key), sehingga untuk membentuk kedua haruslah ditentukan kunci fieldnya. Kunci field haruslah unik dan dapat mewakili atribut lain yang menjadi anggotanya.

d. Bentuk normal ketiga (3NF / Third normal form).

Untuk menjadi normal ketiga maka relasi haruslah dalam bentuk normal kedua dan semua atribut bukan primer tidak punya hubungan yang transitif. Dengan kata lain, setiap atribut bukan kunci haruslah bergantung hanya pada primary 
key dan pada primery key secara menyeluruh.

\section{Microsoft Visual FoxPro}

Microsoft Visual FoxPro, sering disingkat Visual FoxPro, merupakan salah satu perangkat lunak pendukung pemrograman visual. Visual FoxPro merupakan perangkat lunak pemrograman basis data (database).

Dalam buku Abdul Kadir (1998), pengertian database adalah suatu pengorganisasian data dengan tujuan agar data dapat diakses dengan mudah. Dimana pada kenyataannya, umumnya sebuah database terdiri atas sejumlah tabel.

Dalam buku Djajasukma Tjahjadi (1994) disebutkan bahwa Visual FoxPro sebenarnya bukanlah pendatang baru, melainkan penerus generasi sebelumnya (yakni FoxPro for DOS dan FoxPro for Windows). Perintah-perintah dasar yang digunakan oleh Visual FoxPro menyerupai perintah bahasa-bahasa Xbase lainnya. Dengan demikian bagi yang sudah terbiasa dengan dengan bahasa pemrograman seperti dBASE III Plus akan dapat pindah ke Visual FoxPro dengan mudah.

Visual FoxPro menyediakan berbagai fasilitas, sehingga pemrogram dalam membuat program aplikasi sistem informasi menjadi semakin mudah dan cepat dan tentunya hasilnya lebih baik. Beberapa penggunaan Visual FoxPro antara lain :

1. Mengolah data sederhana

2. Membuat program aplikasi sistem informasi sederhana yang berguna bagi suatu perusahaan untuk melakukan kegiatan rutinnya.

3. Membuat program aplikasi sistem informasi perusahaan besar (enterprise) berbasis teknologi client/server.

\section{METODOLOGI}

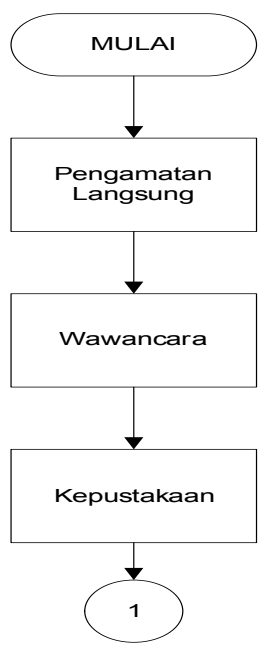




\section{PEMBAHASAN}

\section{Data Flow Diagram (DFD) Usulan}

1.1 Diagram kontek Sistem Usulan

Pada saat calon mahasiswa ingin mendaftar terlebih dahulu harus mengambil formulir pendaftaran di Panitia Penerimaan Mahasiswa Baru (PMB), kemudian panitia PMB mencatat nomor formulir yang telah diambil oleh calon mahasiswa

Setelah calon mahasiswa mengambil formulir pendaftaran kemudian mengisinya dan mengembalikan formulir tersebut serta melengkapi syarat-syarat pendaftaran yang telah ditentukan pada panitia PMB, kemudian Panitia PMB memberikan kartu ujian seleksi kepada calon mahasiswa yang mengembalikan dan melengkapi syarat-syarat pendaftaran. Sebelum Panitia PMB memberikan kartu ujian seleksi terlebih dahulu Panitia PMB mencatat dan memberikan nomor ujian seleksi pada kartu yang akan diberikan kepada calon mahasiswa sebagai kontrol dari calon mahasiswa yang berhak untuk mengikuti ujian seleksi penerimaan mahasiswa baru dan untuk selanjutnya Panitia PMB Mengeluarkan laporan pendaftaran yang kemudian diserahkan kepada Rektor.

Calon mahasiswa yang telah mengembalikan dan melengkapi form pendaftaran harus mengikuti ujian seleksi mahasiswa baru dengan mengisi lembar jawaban dan diserahkan kepada Tim Penyeleksi untuk pemeriksaan lembar jawaban ujian seleksi guna mengetahui lulus tidaknya calon mahasiswa, kemudian tim penyeleksi mengumumkan hasil saringan ujian seleksi pada majalah dinding (mading) universitas.

Setelah calon mahasiswa dinyatakan lulus ujian seleksi maka bila ingin menjadi mahasiswa harus mendaftar ulang dirinya dan membayar biaya Dana Wajib Pendidikan (DWP) yang telah ditetapkan, kemudian Panitia PMB memberikan bukti pembayaran (kwitansi) kepada mahasiswa dan pada akhir penerimaan mahasiswa baru Panitia PMB Mengeluarkan laporan pembayaran dan laporan jumlah mahasiswa baru yang kemudian diserahkan kepada Rektor.

Bagi calon mahasiswa yang telah mendaftar ulang dirinya dan telah melakukan pembayaran DWP yang telah ditetapkan, dinyatakan sah sebagai mahasiswa Unipra dan kemudian Panitia PMB memberikan NPM dan Surat Keterangan Tanda Mahasiswa kepada mahasiswa baru, yang untuk selanjutnya BAAK yang akan memproses Kartu Tanda Mahasiswanya (KTM). Hal ini dapat digambarkan seperti pada gambar 3 dibawah ini :

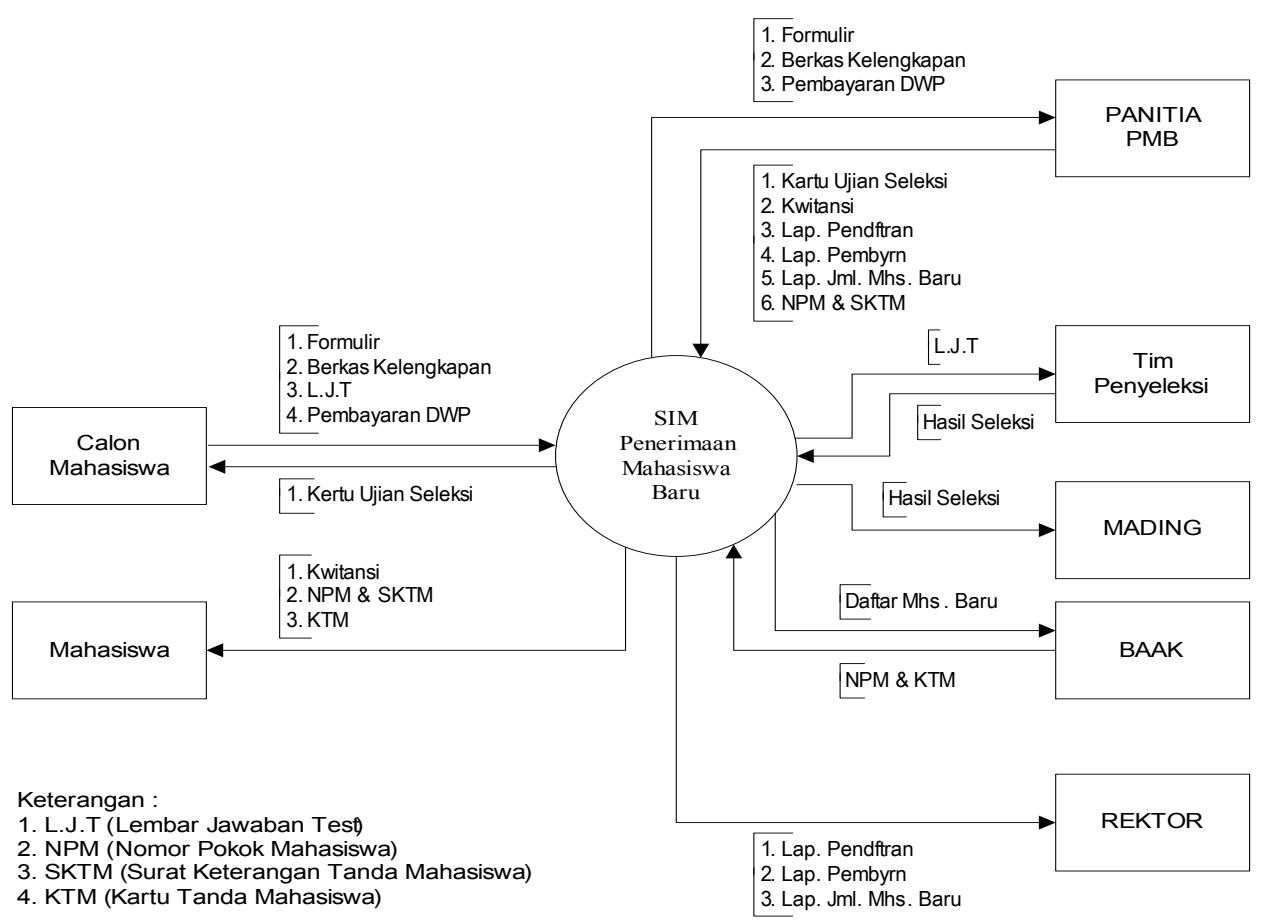




\section{Gambar 3 Diagram Kontek Sistem Usulan}

Sumber : Diolah

\subsection{Diagram Nol Sistem Usulan}

Pada saat calon mahasiswa ingin mendaftar terlebih dahulu harus mengambil formulir pendaftaran di Panitia Penerimaan Mahasiswa Baru (PMB), kemudian panitia PMB memasukkan data calon mahasiswa yang mengambil formulir kedalam database file formulir untuk pembuatan laporan jumlah formulir yang keluar dan kemudian diserahkan kepada Rektor.

Setelah calon mahasiswa mengambil formulir pendaftaran kemudian mengisinya dan mengembalikan formulir tersebut serta melengkapi syarat-syaratpendaftaran yang telah ditentukan pada panitia PMB, kemudian panitia PMB memasukkan data calon mahasiswa yang mengembalikan formulir kedalam database file daftar untuk pembuatan laporan calon mahasiswa yang mengembalikan formulir. Setelah itu kemudian Panitia PMB memberikan kartu ujian seleksi kepada calon mahasiswa yang mengembalikan dan melengkapi syaratsyarat pendaftaran. Sebelum Panitia PMB memberikan kartu ujian seleksi terlebih dahulu Panitia PMB mencatat dan memberikan nomor ujian seleksi pada kartu yang akan diberikan kepada calon mahasiswa sebagai kontrol dari calon mahasiswa yang berhak untuk mengikuti ujian seleksi penerimaan mahasiswa baru dan untuk selanjutnya Panitia PMB Mengeluarkan laporan pendaftaran yang kemudian diserahkan kepada Rektor.

Calon mahasiswa yang telah mengembalikan dan melengkapi form pendaftaran harus mengikuti ujian seleksi calon mahasiswa baru dengan mengisi lembar jawaban ujian seleksi dan menyerahkannya kepada Tim Penyeleksi untuk pemeriksaan lembar jawaban ujian seleksi. Setelah tim penyeleksi memeriksa hasil ujian seleksi para calon mahasiswa selanjutnya Tim penyeleksi memberikan hasil ujian seleksi para calon mahasiswa baru kepada panitia PMB, kemudian panitia PMB memasukkan data hasil koreksi ujian seleksi tersebut kedalam database file seleksi untuk pembuatan laporan hasil seleksi para calon mahasiswa dan kemudian diserahkan kepada Rektor , selanjutnya panitia PMB mengumumkan hasil saringan ujian seleksi calon mahasiswa baru tersebut pada majalah dinding (mading) universitas.

Setelah calon mahasiswa dinyatakan lulus ujian seleksi maka bila ingin menjadi mahasiswa harus mendaftar ulang dirinya dan membayar biaya Dana Wajib Pendidikan (DWP) yang telah ditetapkan, selanjutnya panitia PMB memasukkan data mahasiswa yang membayar DWP kedalam database file bayar untuk pembuatan laporan calon mahasiswa yang membayar DWP dan kemudian diserahkan kepada Rektor, kemudian Panitia PMB memberikan bukti pembayaran (kwitansi) kepada calon mahasiswa baru yang telah membayar DWP.

Bagi calon mahasiswa yang telah melakukan pembayaran DWP yang telah ditetapkan, dinyatakan sah sebagai mahasiswa Unipra. Selanjutnya panitia PMB memasukkan data calon mahasiswa yang telah melakukan pembayaran DWP kedalam database file mahasiswa untuk pemberian Nomor Pokok Mahasiswa (NPM) dan untuk pembuatan laporan jumlah mahasiswa baru yang kemudian diserahkan kepada Rektor. Setelah itu panitia PMB memberikan Surat Keterangan Tanda Mahasiswa (SKTM) kepada para mahasiswa baru, yang untuk selanjutnya BAAK yang akan memproses Kartu Tanda Mahasiswanya (KTM). Hal ini dapat digambarkan seperti pada gambar 4 dibawah ini : 


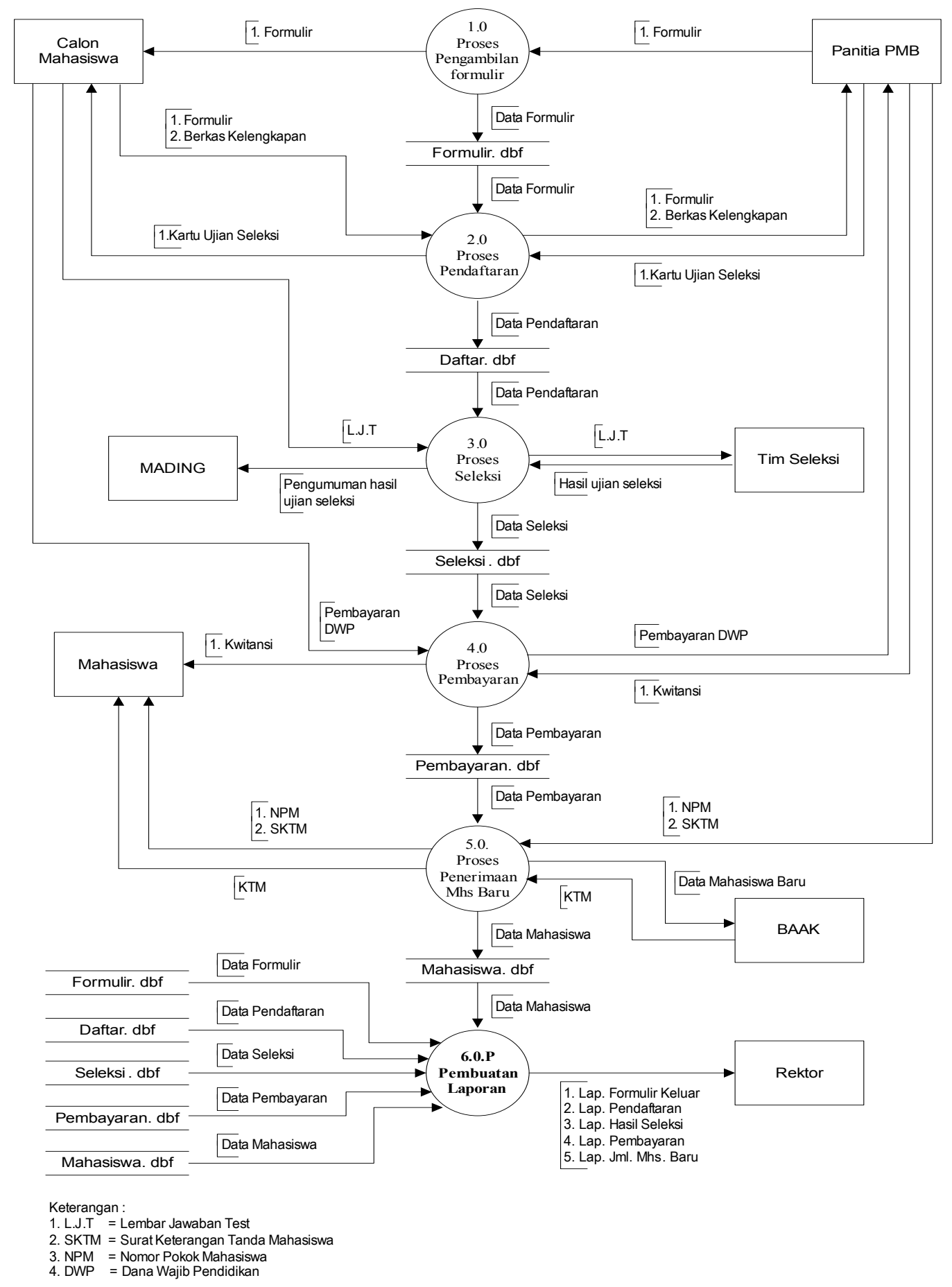

Gambar 4 Diagram Nol Sistem Usulan

Sumber : Diolah 


\section{Entity Relationship Diagram (ERD)Usulan}

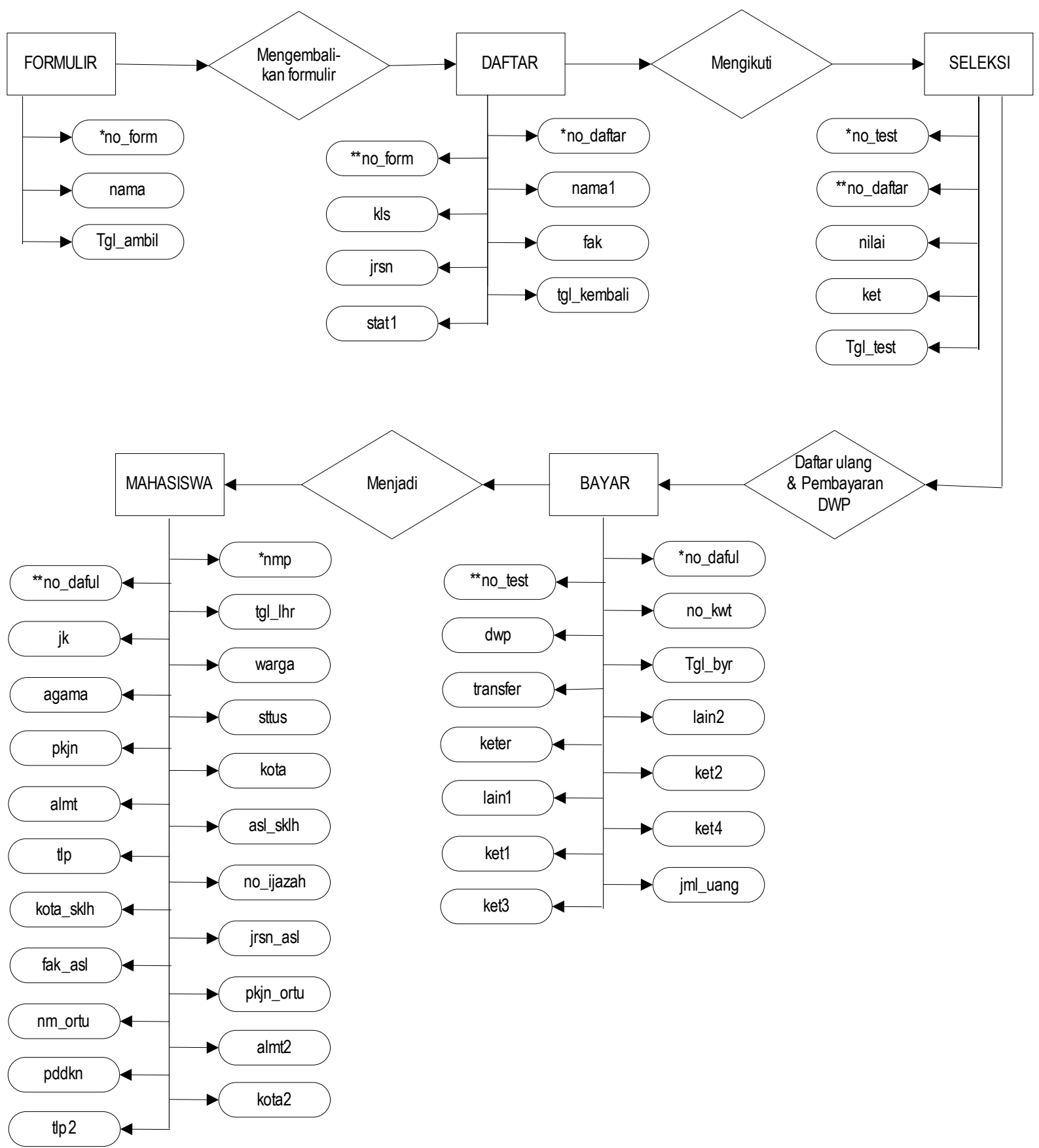

Gambar 5 Entity Relationship Diagram (ERD) Sistem Usulan

Sumber : Diolah 


\section{Tampilan Input}

\section{a. Menu_Utama.mpr}

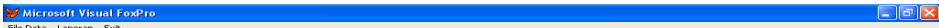

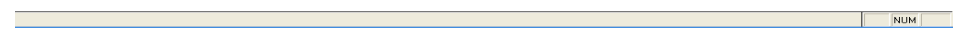

Gambar 6 Tampilan Menu Utama

Sumber : Display menu_utama.mpr

b. Form f_formulir.scx
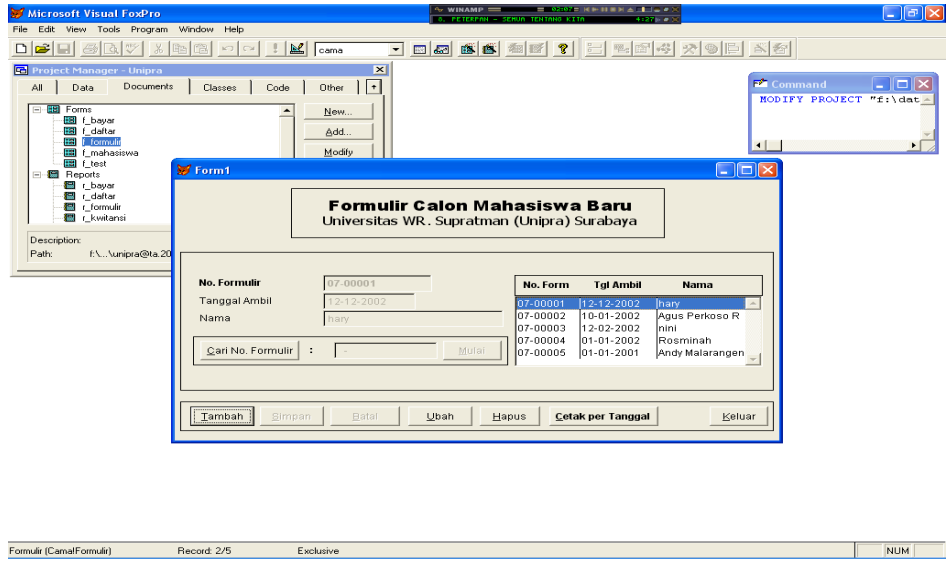

Gambar 7 Tampilan Form Formulir

Sumber : Display f_formulir.scx

\section{c. Form f daftar.scx}
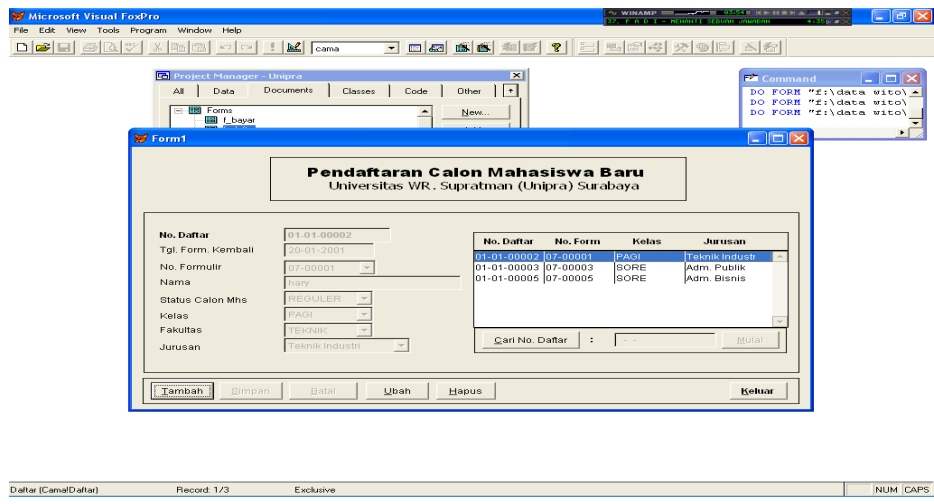

Gambar 8 Tampilan Form Daftar

Sumber : Display f_daftar.scx 


\section{d. Form f_test.scx}
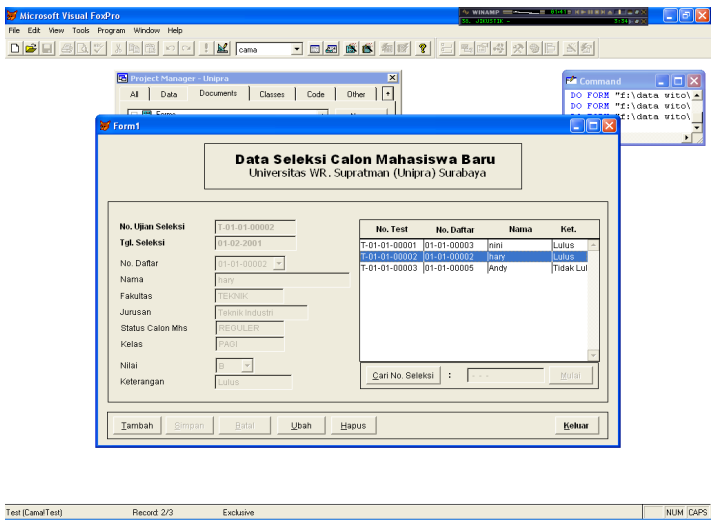

Gambar 9 Tampilan Form Seleksi Sumber : Display f_test.scx

\section{e. Form f bayar.scx}

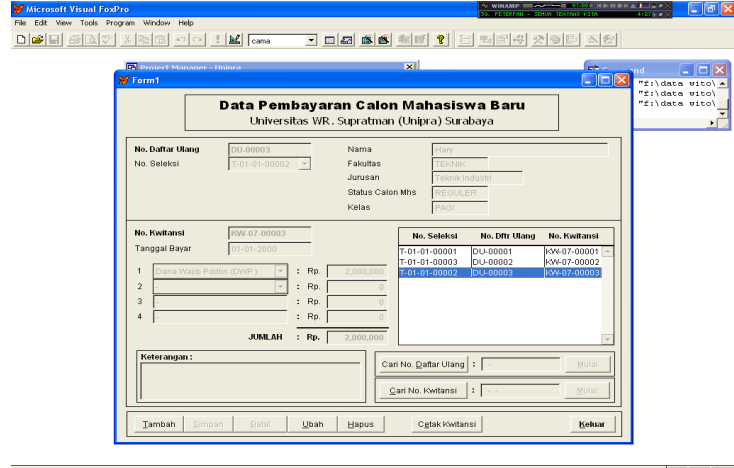

Gambar 10 Tampilan Form Bayar

Sumber : Display f_bayar.scx

\section{f. Form f_mahasiswa.scx}
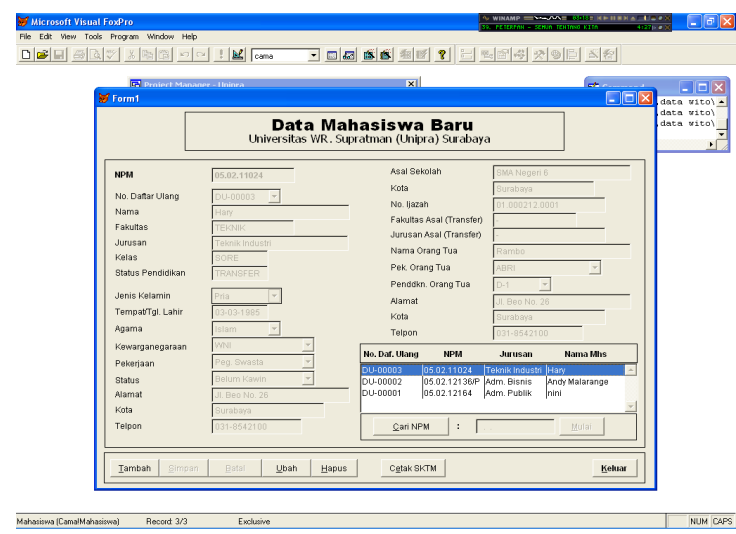

Gambar 11 Tampilan Form Mahasiswa

Sumber : Display f mahasiswa.scx 


\section{Tampilan Output}

\section{a. Laporan r_formulir.frx}

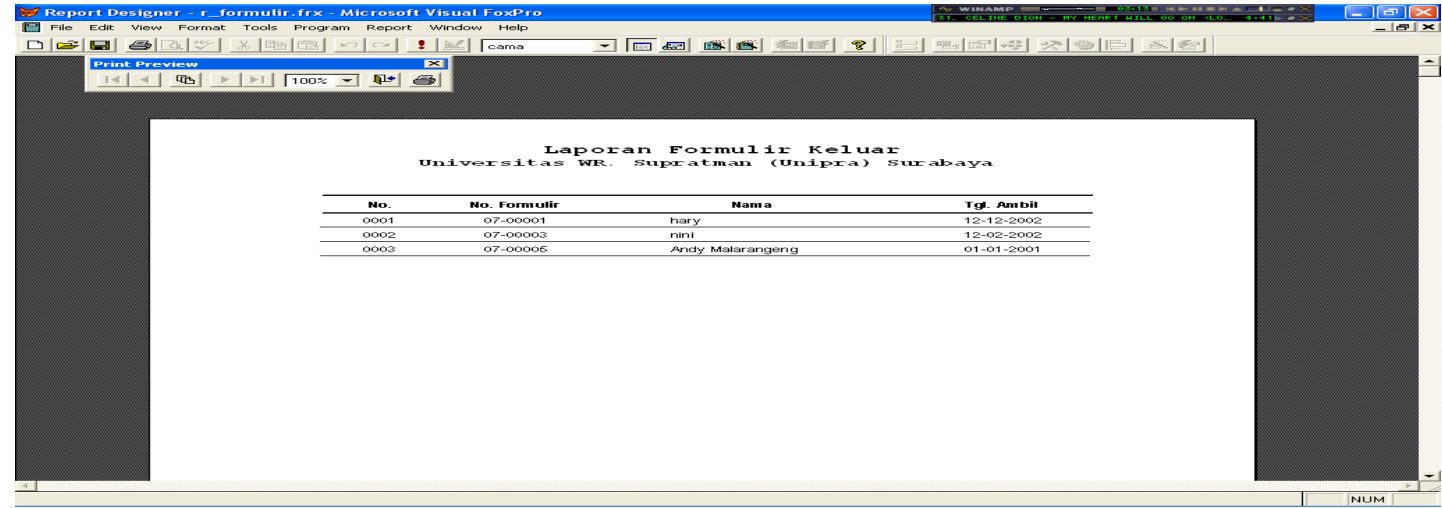

Gambar 12 Tampilan Laporan Jumlah Formulir Keluar

Sumber : Display Laporan $\mathrm{r}_{-}$formulir.frx

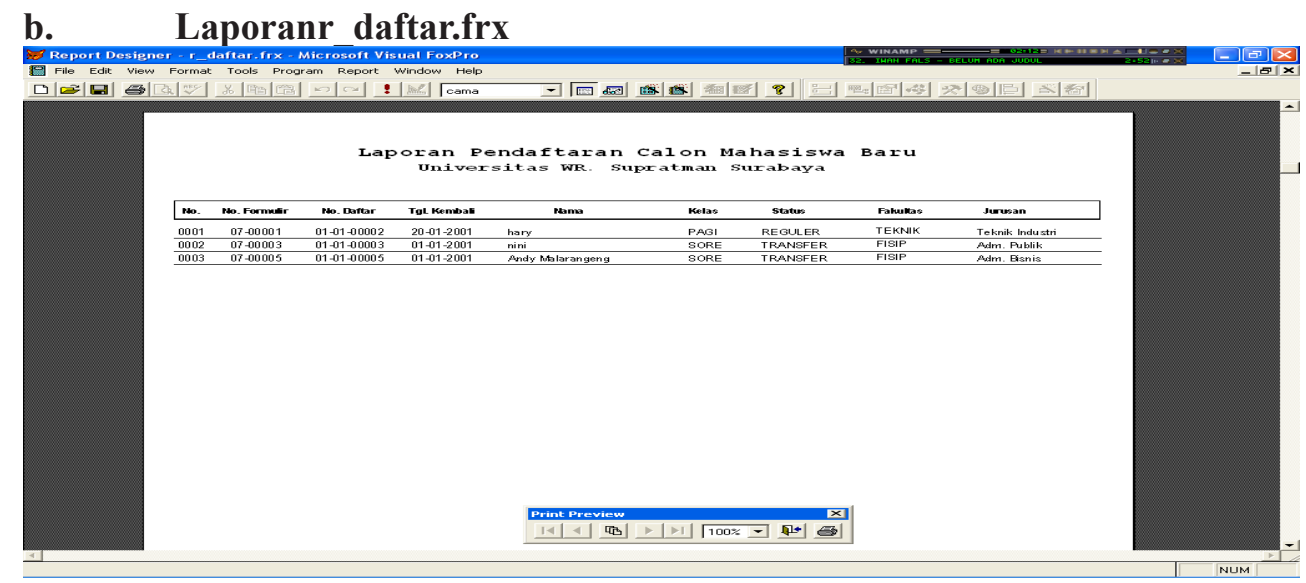

Gamber 13 Tampilan Laporan Jumlah Pendaftar

Sumber : Display Laporan r_daftar.frx

\section{c. Laporan $r$ test.frx}

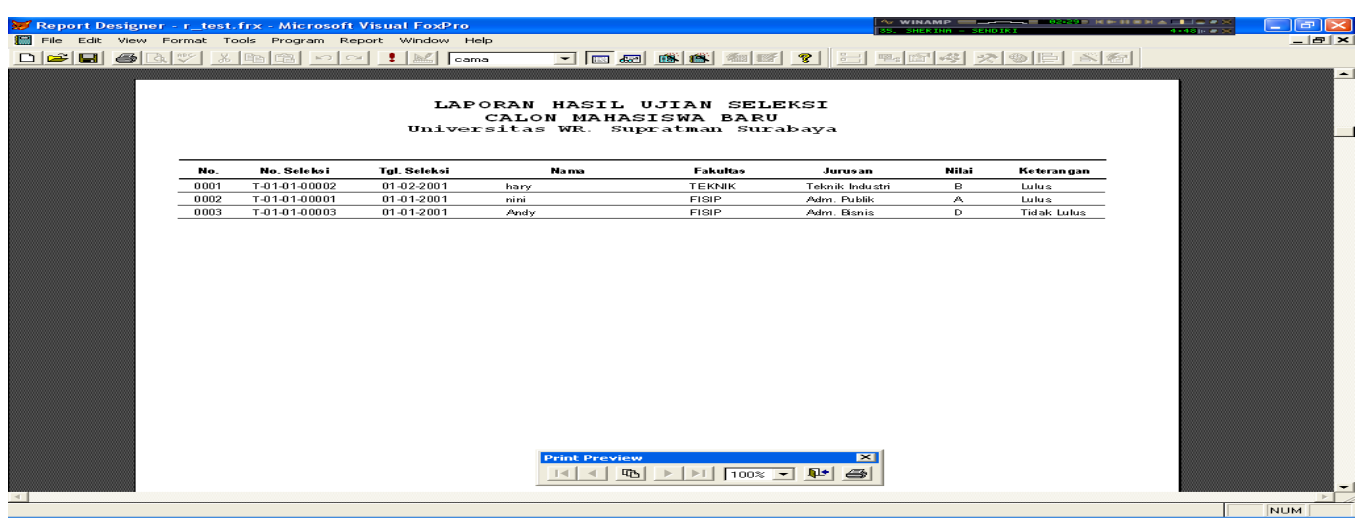

Gambar 14 Tampilan Laporan Hasil Seleksi

Sumber : Display Laporan r_test.frx 
d. Laporan r_kwitansi.frx

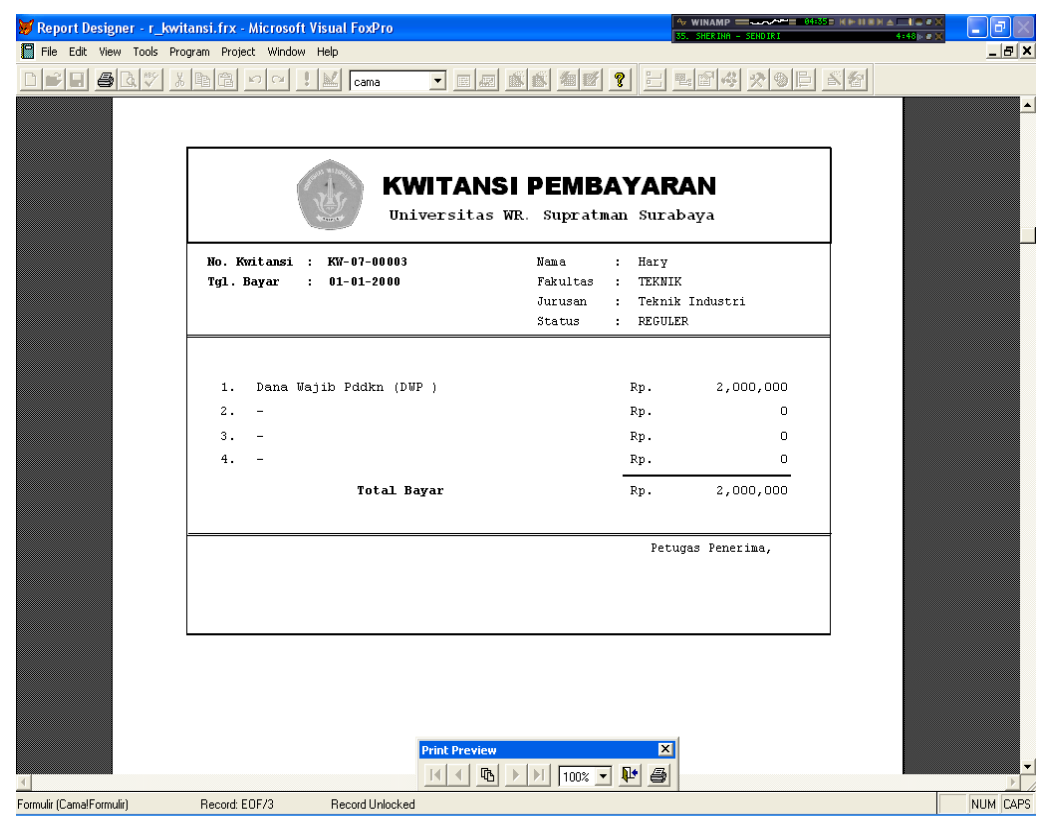

Gambar 15 Tampilan Laporan Kwitansi Pembayaran Sumber : Display Laporan r_kwitansi.frx

e. Laporan r_bayar.frx

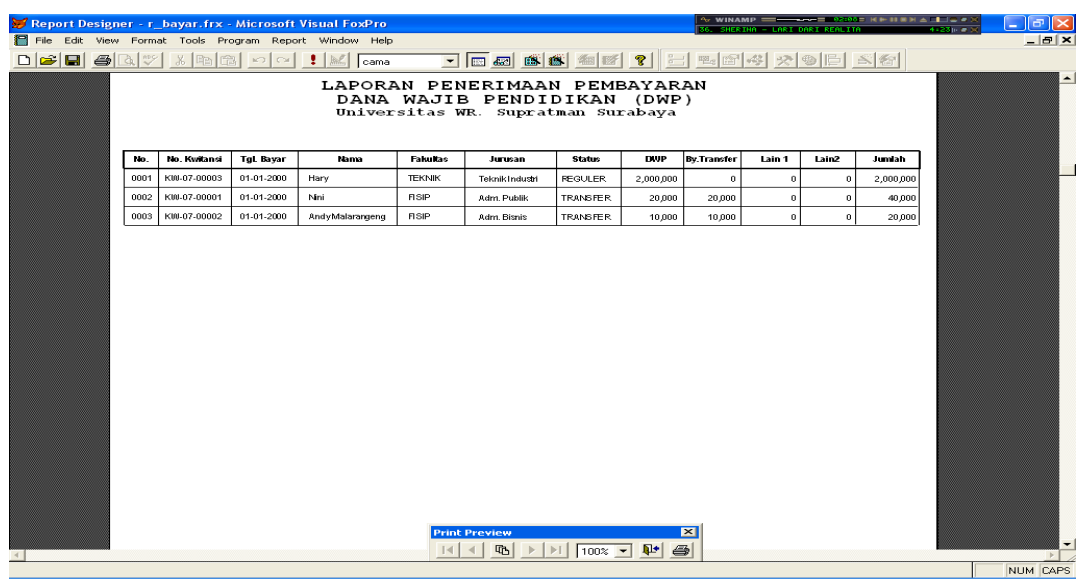

Gambar 16 Tampilan Laporan Jumlah Pembayaran

Sumber : Display Laporan r_bayar.frx 


\section{f. Laporan r_mhs.frx}

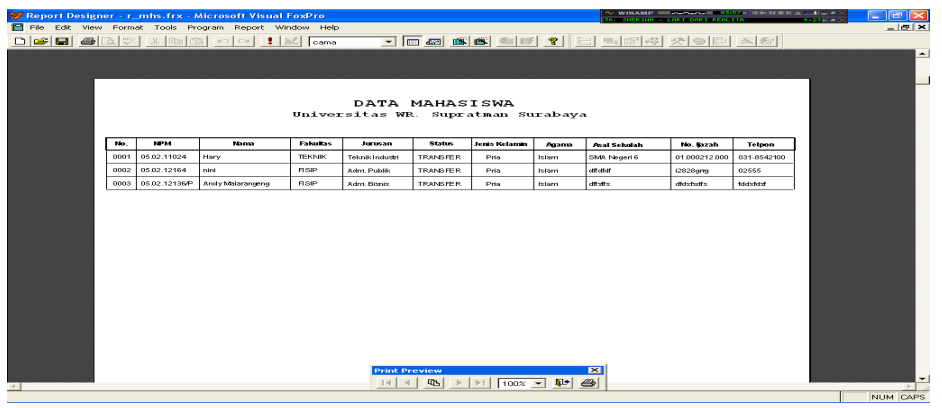

Gambar 17 Tampilan Laporan Jumlah Mahasiswa Baru Sumber : Display Laporan r_mhs.frx

\section{Spesifikasi Sistem Komputer}

Perangkat Keras (Hardware)

Dalam pengoperasian sistem, diperlukan perangkat pembantu yang gunanya adalah untuk memperlancar dan mempercepat proses pengoperasian dari sistem yang diajukan. Adapun perangkat tersebut adalah :

$\begin{array}{ll}\text { * CPU } & : \\ \circ \quad \begin{array}{l}\text { Processor } \\ 2.66 \mathrm{Ghz}\end{array} & \text { : Intel Pentium IV, } \\ \circ \quad \text { Hard Disk } & : \text { Seagate } 80 \mathrm{~Gb} \\ \circ \quad \text { Memory } & : 256 \mathrm{MB} \text { RAM } \\ \text { ○ Floppy Disk Drive } & : \text { : } 1.44 \mathrm{MB} \\ \text { * Monitor } & : \text { LG / SVGA } \\ \text { * Keyboard } & : \text { Logitech } 108 \\ \text { keys } & \\ \text { * Printer } & : \text { Lexmark Z-515 }\end{array}$

Perangkat Lunak (Software)

Software yang digunakan dalam pembuatan sistem saat ini adalah :

* Sistem Operasi : Microsoft Window XP SP2

* Paket Program : : Microsoft Visual Fox Pro 6.0

\section{KESIMPULAN}

Dengan adanya sistem pengolahan data yang baik, maka kesalahan-kesalahan mendasar yang sering terjadi akan dapat dihindarkan dan bahkan dihilangkan. Selain hal tersebut, proses pengambilan keputusan juga akan lebih cepat dan lebih akurat, karena fasilitas pembuatan laporan telah tersedia sehingga laporan dapat dilakukan setiap saat.

Dengan adanya usulan sistem pengolahan data yang dirancang ini, maka beban kerja Panitia penerimaan mahasiswa baru akan berkurang dan akan meningkatkan mutu pelayanan dibidang penerimaan mahasiswa baru di Universitas WR. Supratman Surabaya.

\section{DAFTAR PUSTAKA}

1. Abdul Kadir [1998], Pemrograman Basis Data dengan Visual FoxPro 5.0, Penerbit Andi Yogyakarta, Yogyakarta.

2. AMIK Andalan Jakarta [2003], "Sistem Basis Data" Panduan materi mata kuliah Manajemen Basis Data, AMIK Andalan Jakarta.

3. Anjar Hariyanto [2004], "Perancangan Sistem Informasi Manajemen Rawat Inap Pada Rumah Sakit Islam Jakarta" Tugas Akhir, Teknik Industri, Universitas Surapati, Jakarta

4. Budi Santoso [2004], Panduan Lengkap Pemrograman Visual Foxpro, Penerbit Andi Yogyakarta, Yogyakarta.

5. Djajasukma Tjahjadi [2004], Mengelola Data Dengan Visual FoxPro 8.0, Penerbit Andi Yogyakarta, Yogyakarta.

6. HM. Jogiyanto [1993], Analisa dan Desain Sistem Informasi : Pendekatan Terstruktur, Penerbit Andi Offset, Yogyakarta

7. Gerald, Jerry Fitz [1992], Sistem Informasi 
Manajemen I \& II, Penerbit Pustaka Binawan, Jakarta.

8. Jogiyanto Hartono [1998], Sistem Informasi Manajemen, Penerbit Andi Yogyakarta, Yogyakarta.

9. JogiyantoHartono [1999], PengenalanKomputer : Dasar Ilmu Komputer, Pemrograman, Sistem Informasi dan Intelegensi Buatan, Penerbit Andi Yogyakarta, Yogyakarta.

10.Jogiyanto Hartono [1999], Sistem Informasi dan Intelegensi Buatan, Penerbit Andi Yogyakarta, Yogyakarta.

11. Khairul Fatikhin [2005], "Komputerisasi Sistem Penerimaan Mahasiswa Baru Pada Madrasah Aliyah As-Syafiiyah 02 Jakarta" Tugas Akhir, AMIK Andalan Jakarta, Jakarta

12.Tavri D. Mahyusir [1989], Analisa Perancangan Sistem Pengolahan Data, Penerbit PT. Elex Media Komputindo, Jakarta.

13.Tavri D. Mahyusir [1992], Pengolahan Data, Penerbit PT. Elex Media Komputindo, Jakarta.

14.Tata Sutabri [2003], Sistem Informasi Manajemen, Penerbit Andi Yogyakarta, Yogyakarta.

15.Tjahjadi Sukma Jaja [2004], Mengelola Data Dengan Visual Foxpro 8.0, Penerbit : Andi Yogyakarta, Percetakan : Andi Offset, Yogyakarta. 